\title{
Development, growth, and yolk utilization of hatchery-reared red snapper Lutjanus campechanus larvae
}

\author{
Kresimir Williams ${ }^{1,3, *}$, Nikolaos Papanikos ${ }^{1}$, Ronald P. Phelps ${ }^{1}$, Judith D. Shardo ${ }^{2}$ \\ ${ }^{1}$ Department of Fisheries and Allied Aquacultures, Auburn University, Auburn, Alabama 36849, USA \\ ${ }^{2}$ Department of Biology, Middle Tennessee State University, Murfreesboro, Tennessee 37132, USA \\ ${ }^{3}$ Present address: 7600 Sand Point Way NE, Building 4, Seattle, Washington 98115, USA
}

\begin{abstract}
The development of yolk-sac larvae of red snapper Lutjanus campechanus from endogenous utilization of nutrient sources to the development of feeding ability is described, with the aim of better understanding the high mortalities observed at first-feeding. Larvae from several spawns were reared at a salinity of 31 and a temperature of $28^{\circ} \mathrm{C}$. Yolk utilization rate, changes in body parameters and the development of morphological characters were observed. Maximum standard length $\left(\mathrm{L}_{\mathrm{S}}\right)$ and body depth were observed concurrently with yolk-sac exhaustion at $56 \mathrm{~h}$ postfertilization (hpf). A decrease in $\mathrm{L}_{\mathrm{S}}$, body width and body depth was observed following yolk-sac exhaustion. Orbit pigmentation, followed by jaw articulation, were observed at 65 hpf. Substantial cranial and body cavity development occurred in the absence of visible yolk material. Complete absence of visible yolk-sac material and less than $2 \%$ of the oil globule volume at hatching were observed at the time of development of feeding ability. This indicates an absence of a transitional feeding period and the critical nature of first-feeding in this species within controlled environments.
\end{abstract}

KEY WORDS: Red snapper · Larval development · Yolk utilization · Endogenous reserves

\section{INTRODUCTION}

Red snapper Lutjanus campechanus is an economically important species in the Gulf of Mexico, targeted by both commercial and recreational fishing. Heavy exploitation of natural stocks coupled with continuing market demand has increased interest in the possibility of stock enhancement and the commercial culture of this species. However, current red snapper culture and stock enhancement activities are constrained by variable and generally low larval survival. Overall larval development of red snapper has been described after successful spawning in controlled conditions was first accomplished by Rablais et al. (1980), and the development process through metamorphosis was outlined by Bootes (1998). Due to the high mortalities that are continually associated with the establishment of feeding, a more detailed study of the morphological processes associated with early larval development was conducted.

In snapper larvae, 2 periods of high mortality are recognized, the first corresponding with the changeover of energy sources and first-feeding at 3 to $8 \mathrm{~d}$ post-hatch, and the second taking place around $20 \mathrm{~d}$ post-hatch, which may be caused by physiological changes at the onset of metamorphosis (Lim et al. 1985, Emata et al. 1994). The identification and availability of appropriate first-feeding organisms is of primary interest, as is optimizing the efficiency of endogenous resource-use through the control of environmental parameters.

The transitional feeding period in larvae is defined as an interval in which feeding ability has been developed and feeding commences, with some reserves still present to meet the energetic demands of prey capture (Moteki et al. 2001). The initial prey capture success is 
presumably low, and the energetic cost of searching and capturing prey is substantial (Blaxter 1986). The spawns of highly fecund marine finfish are characterized by small eggs and larvae and a limited transitional feeding period. This means minimal nutrient reserves at first-feeding, which may influence captive larval rearing success.

Changes in standard length $\left(\mathrm{L}_{\mathrm{S}}\right)$ through endogenous feeding have been used as a relative measure of yolk conversion efficiency (Watanabe et al. 1998), and allow inferences to be made on larval conditions in combination with other measured characters (Reichow et al. 1991). Rogers \& Westin (1981) suggested that tissues of striped bass larvae may be mobilized for metabolic demands before the oil globule is completely consumed, indicating a strategy of lipid conservation. Changes in morphometry can be used as indices of tissue mobilization and yolk utilization rates, providing inexpensive, real-time information about relative larval condition.

The goals of this study were to describe the functional development of red snapper larvae to the end of the yolk-sac stage, with an emphasis on the transition of nutrient sources. Understanding the limitations of endogenous resources in larvae, especially in new culture-species, may help aquaculturists construct an appropriate management framework to maximize larval rearing success, and provide additional understanding of early life histories critical to recruitment studies.

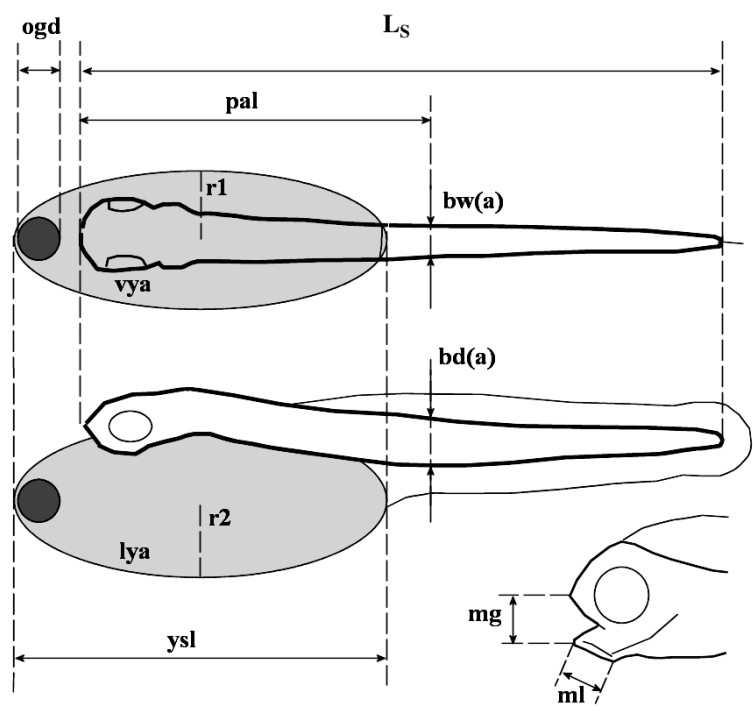

Fig. 1. Lutjanus campechanus. Measurements of yolk-sac larvae. bd(a): body depth at anus; bw(a): body width at anus; $\mathrm{L}_{\mathrm{S}}$ : standard length; lya: lateral yolk sac area; mg: maximum gape; ml: mandibular length; ogd: oil globule diameter; pal: pre-anal length; r1: radius of yolk-sac ventral ellipsoid (calculated); r2: radius of yolk-sac lateral ellipsoid (calculated); vya: ventral yolk-sac area; ysl: yolk-sac length

\section{MATERIALS AND METHODS}

Spawning, egg and larval management. The red snapper larvae used in this study were reared from 3 separate induced (Minton et al. 1983) spawns on June 26, July 11 and July 26, 2001 of wild broodstock at the Claude Peteet Mariculture Center in Gulf Shores, Alabama. Fertilized eggs were placed into 601 aquaria and maintained in recirculated, lightly aerated seawater (31.3) flowing into aquaria at approximately $100 \mathrm{ml} \mathrm{min}{ }^{-1}$ and a temperature of $28 \pm 0.5^{\circ} \mathrm{C}$. Larval stocking density was 100 to 200 ind. $\mathrm{l}^{-1}$. Larval densities were measured by calculating a mean larval count from 10 volumetric aliquots taken throughout the aquarium.

Morphometric data collection. All morphometric measurements were made from images of live larvae. Samples consisted of 5 to 10 larvae, sampled randomly from rearing tanks. Larvae were individually placed under a stereomicroscope outfitted with a black and white digital camera, and the images were captured and stored on a PC in a $632 \times 480$ tagged image-format file; 3 images at different magnifications were taken of each larva in order to maximize resolution of measured features and provide lateral and ventral views of each individual for yolk-sac calculation. Measurements were made using Optimas ${ }^{\circledR}$ image analysis software calibrated with a stage micrometer.

Yolk-sac volume calculation. Yolk-sac volume was derived from measurements of area of the yolk-sac using the ventral and lateral views of the larva (Fig. 1). From 2 area measurements and the overall length of the yolk-sac, the radii of the ellipsoidal solid were calculated for both width and height of the yolk-sac. The length of the yolk-sac was measured directly. A volumetric formula for an ellipsoidal solid was used:

$$
V=(4 / 3 \pi) \times r_{1} \times r_{2} \times r_{3}
$$

where $r_{1}, r_{2}$, and $r_{3}$ are the half-width, half-height and half-length of the yolk-sac, respectively. The oil globule volume was derived from the volumetric formula of a sphere, using the mean of 2 diameter measurements to derive the radius. All statistical analyses were performed using SAS Version 8.2 software.

\section{RESULTS}

\section{Yolk utilization rate}

The rate of yolk mass reduction in red snapper larvae was rapid, with exhaustion of the yolk-sac resources preceding that of the oil globule. The mean volume of yolk at hatch represented around $45 \%$ of the volumetric yolk content of the fertilized egg. The 

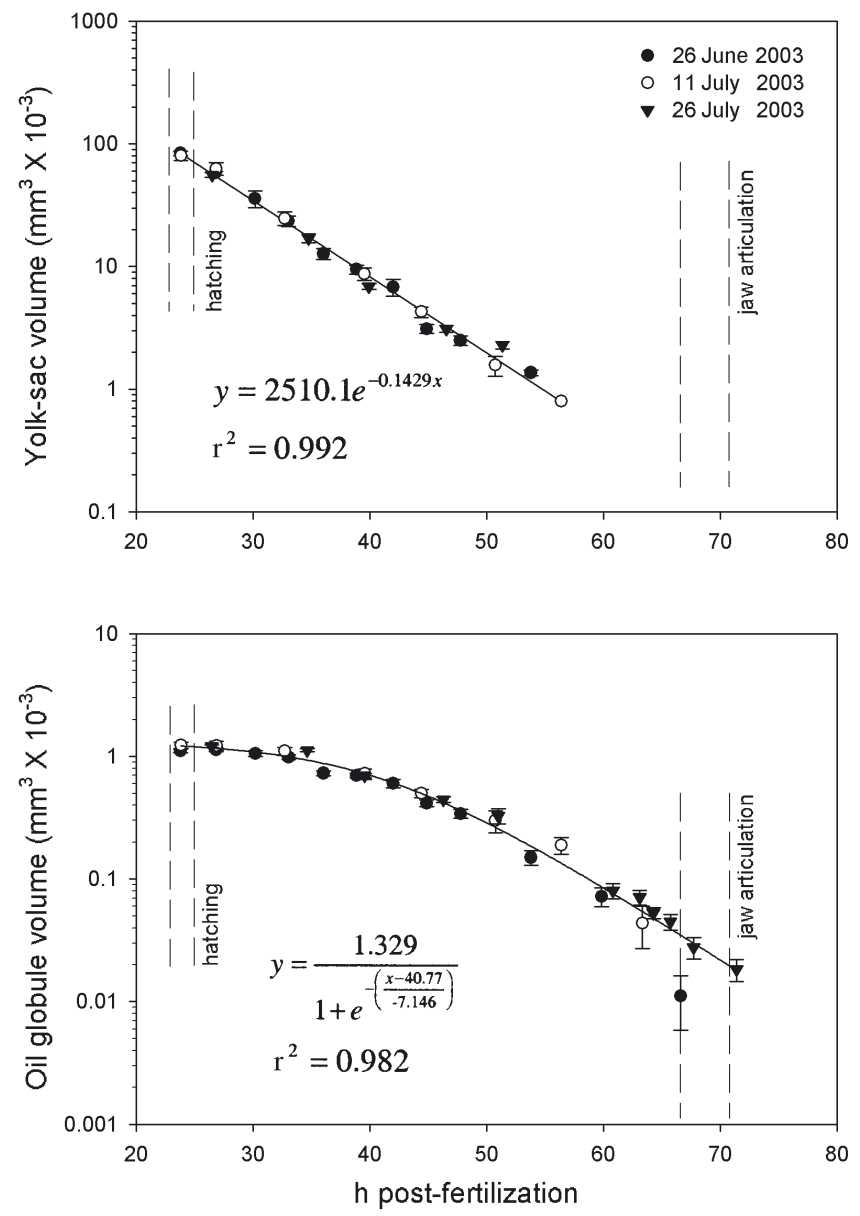

Fig. 2. Lutjanus campechanus. Yolk-sac and oil-globule utilization patterns of yolk-sac larvae; 3 separate rearing trials. Data are means \pm SE of 5 to 10 larvae; where not visible, SE is masked by symbol

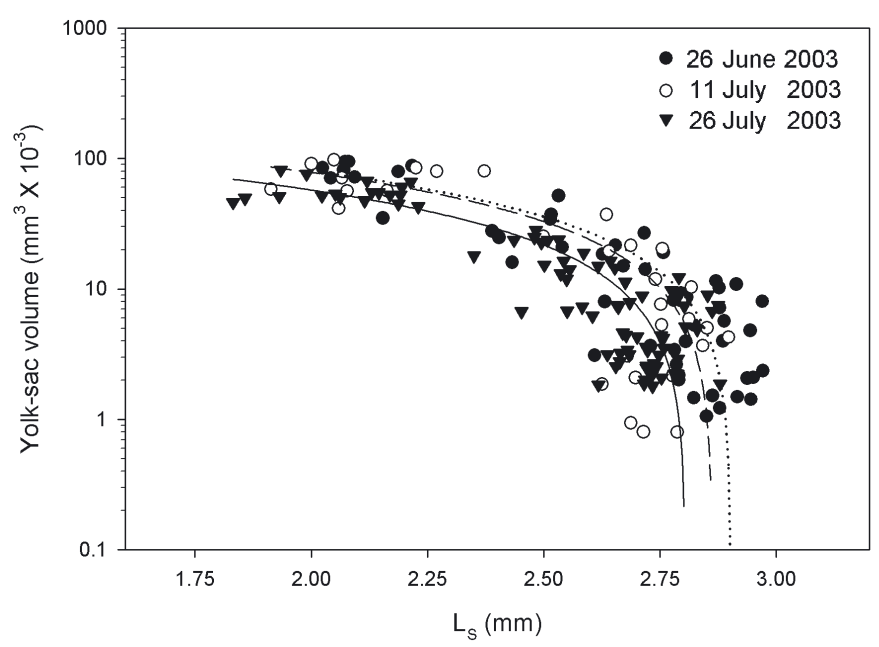

Fig. 3. Lutjanus campechanus. Relationship of $\mathrm{L}_{\mathrm{S}}$ (standard length) to yolk-sac volume. Data points represent individual larvae from 3 rearing trials. Relationship is modeled by linear regression. Note logarithmic axis for yolk volume rates of volumetric loss of yolk and the oil globule measurably diverged through development, indicating stage-specific endogenous resource use. Nonlinear regressions were used for determining endogenous resource endpoints, as these are difficult to observe directly. Utilization rate models are usually asymptotic, so the exhaustion of yolk resources was approximated at $1 \%$ of the initial level, observed around $56 \mathrm{~h}$ post-fertilization (hpf) (Fig. 2). At the time of full eye pigmentation, the remaining oil globule volume is low and is fully consumed in most individuals when feeding ability has developed, with an overall mean value of $2 \%$.

Utilizing the ventral aspect of the yolk-sac in addition to the most common approach of measuring yolksac height and length from the lateral view increases the accuracy of yolk-sac volume estimation. The yolksac area measured from the ventral image of the larva was greater than the lateral measurement for almost all individuals, with the difference averaging $14.5 \%$ over the measurement period $(36 \mathrm{~h})$, indicating a potential source of bias with this species when utilizing only lateral measurements of the yolk-sac.

As the yolk resources became reduced, the rate of utilization as well as the increase in length slowed down linearly. There were differences among spawns in the efficiency of yolk conversion to tissue with respect to $L_{S}$ attained (Fig. 3). This may have been an environmental or genetic effect, but a meaningful comparison was not within the scope of this study.

\section{Morphometry}

Body length and depth displayed an initial increase, reaching maximal length prior to the final stage of yolk-sac utilization followed by a gradual decrease (Fig. 4). The magnitude of the decrease in $\mathrm{L}_{\mathrm{S}}$ was also reflected in the pre-anal segment of the length, possibly due to the retraction of the digestive tract as opposed to reduction in overall notochord length. Lateral compression of the body was observed, as the approximately circular body cross-section after hatch became elliptical. Mean $\mathrm{L}_{\mathrm{S}}$ among all spawns measured near hatching (24 hpf) was $2.09 \pm 0.02 \mathrm{~mm}$, and the maximum mean $\mathrm{L}_{\mathrm{S}}$ of any sample was $2.84 \mathrm{~mm}$, which was observed at $42 \mathrm{hpf}$. Head length (measured from posterior margin of otic vesicle to tip of snout) increased gradually during the entire measurement period from $414.4 \pm 2.0 \mu \mathrm{m}$ at hatching to $481.4 \pm$ $10.3 \mu \mathrm{m}$ at $120 \mathrm{hpf}$. After initial mouth articulation, the jaw structures continued to develop, although the increase in length of the mandible and snout from 95 to 120 hpf was not significant, with $\mathrm{p}=0.07$ and $\mathrm{p}=0.15$, respectively (Table 1). 


\section{Development}

Table 2 describes developmental stages of the larvae from hatching to complete exhaustion of the endogenous resources and the characteristics of each stage as reflected in the developmental progression of morphometric characters (Table 2). Representative larvae were chosen to illustrate developmental stages observed during the course of the study (Fig. 5). Red snapper eggs measured 0.75 to $0.80 \mathrm{~mm}$ in diameter at $12 \mathrm{hpf}$. The observed hatching interval of red snapper incubated at $28^{\circ} \mathrm{C}$ did not vary among the separate spawning events, with $>90 \%$ of larvae emerging between 23 and 25 hpf. Development was tracked using fertilization time, as hatching in red snapper occurs within a specific time interval and is not strictly linked to the developmental progression of the embryo as in many fish species (Kimmel et al. 1995).
Table 1. Lutjanus campechanus. Relative body proportions and jaw-development measurements of yolk-sac larvae (means \pm SE). hpf: hours post-fertilization; HL:BL = ration head length:body length; Pre-anal L:BL = ratio pre-anal length:body length; HD:BD = ratio head depth:body depth

\begin{tabular}{|lccccc|}
\hline $\begin{array}{c}\text { Time } \\
(\mathrm{hpf})\end{array}$ & HL:BL & Pre-anal L:BL & HD:BD & $\begin{array}{c}\text { Max. } \\
\text { gape }(\mu \mathrm{m})\end{array}$ & $\begin{array}{c}\text { Mandibular } \\
\text { length }(\mu \mathrm{m})\end{array}$ \\
\hline 24 & $0.20 \pm 0.001$ & $0.52 \pm 0.005$ & $1.16 \pm 0.017$ & - & - \\
36 & $0.16 \pm 0.004$ & $0.45 \pm 0.008$ & $1.68 \pm 0.023$ & - & - \\
48 & $0.15 \pm 0.003$ & $0.43 \pm 0.004$ & $1.87 \pm 0.043$ & - & - \\
60 & $0.15 \pm 0.002$ & $0.41 \pm 0.005$ & $2.10 \pm 0.070$ & $180 \pm 15$ & $221 \pm 13$ \\
72 & $0.17 \pm 0.004$ & $0.40 \pm 0.010$ & $2.39 \pm 0.167$ & $185 \pm 16$ & $252 \pm 8$ \\
95 & $0.18 \pm 0.003$ & $0.39 \pm 0.013$ & $2.38 \pm 0.065$ & $175 \pm 25$ & $254 \pm 15$ \\
120 & - & - & - & $190 \pm 28$ & $260 \pm 13$ \\
\hline
\end{tabular}

\section{Survival}

Hatching and survival through the endogenous stage were monitored with a single spawn that was assumed to be representative of rearing success for induced spawned red snapper eggs and larvae in the hatchery. Significant mortalities were observed during incubation and pre-feeding development; hatchout percent was $66.7 \pm 6.2 \%$, and survival to the formation of mouth parts was $37 \pm 1.6 \%$.
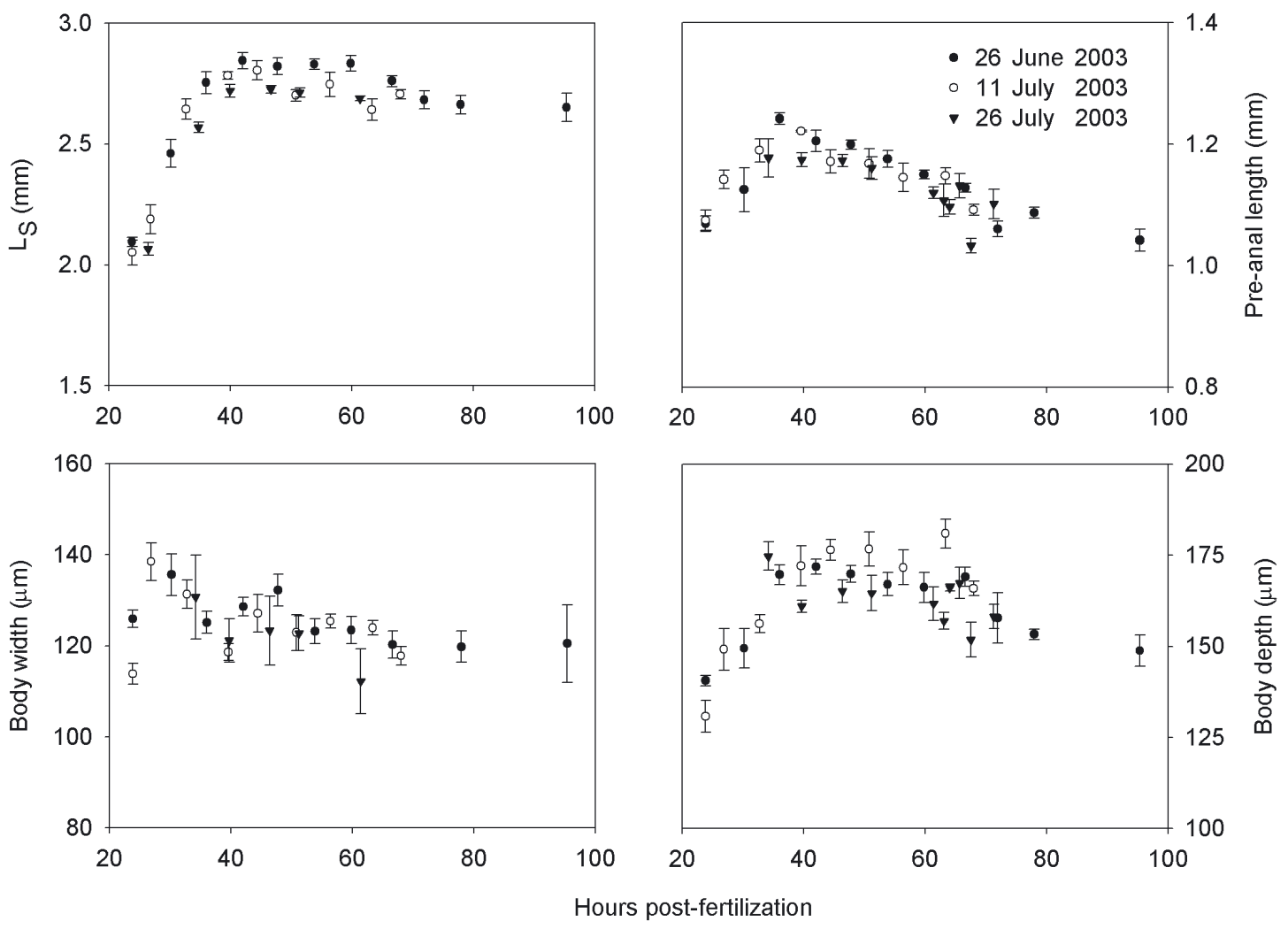

Fig. 4. Lutjanus campechanus. Body parameters of yolk-sac larvae; 3 separate rearing trials. Data are means \pm SE of 5 to 10 larvae; where not are visible, SE is masked by symbol 


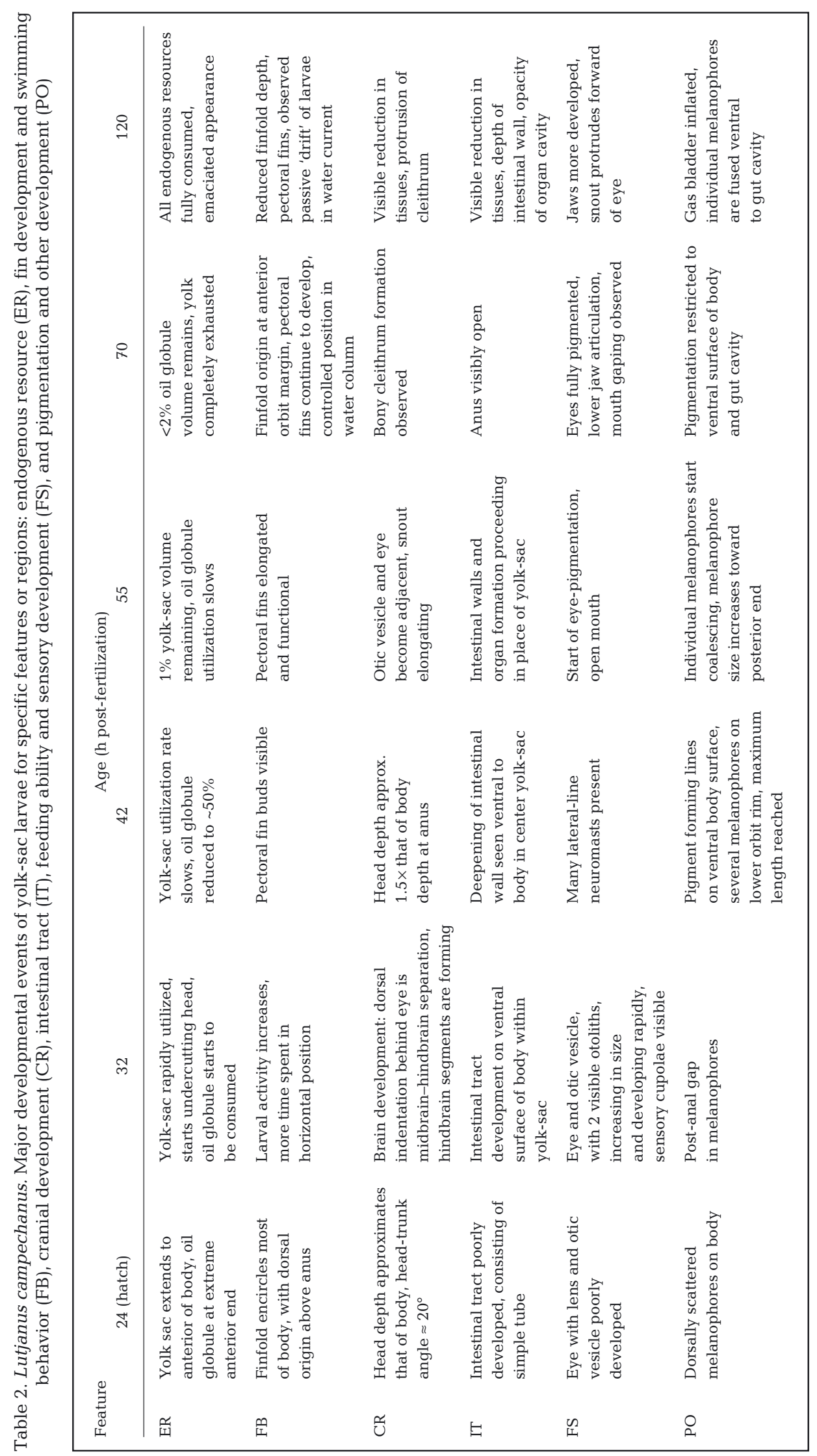




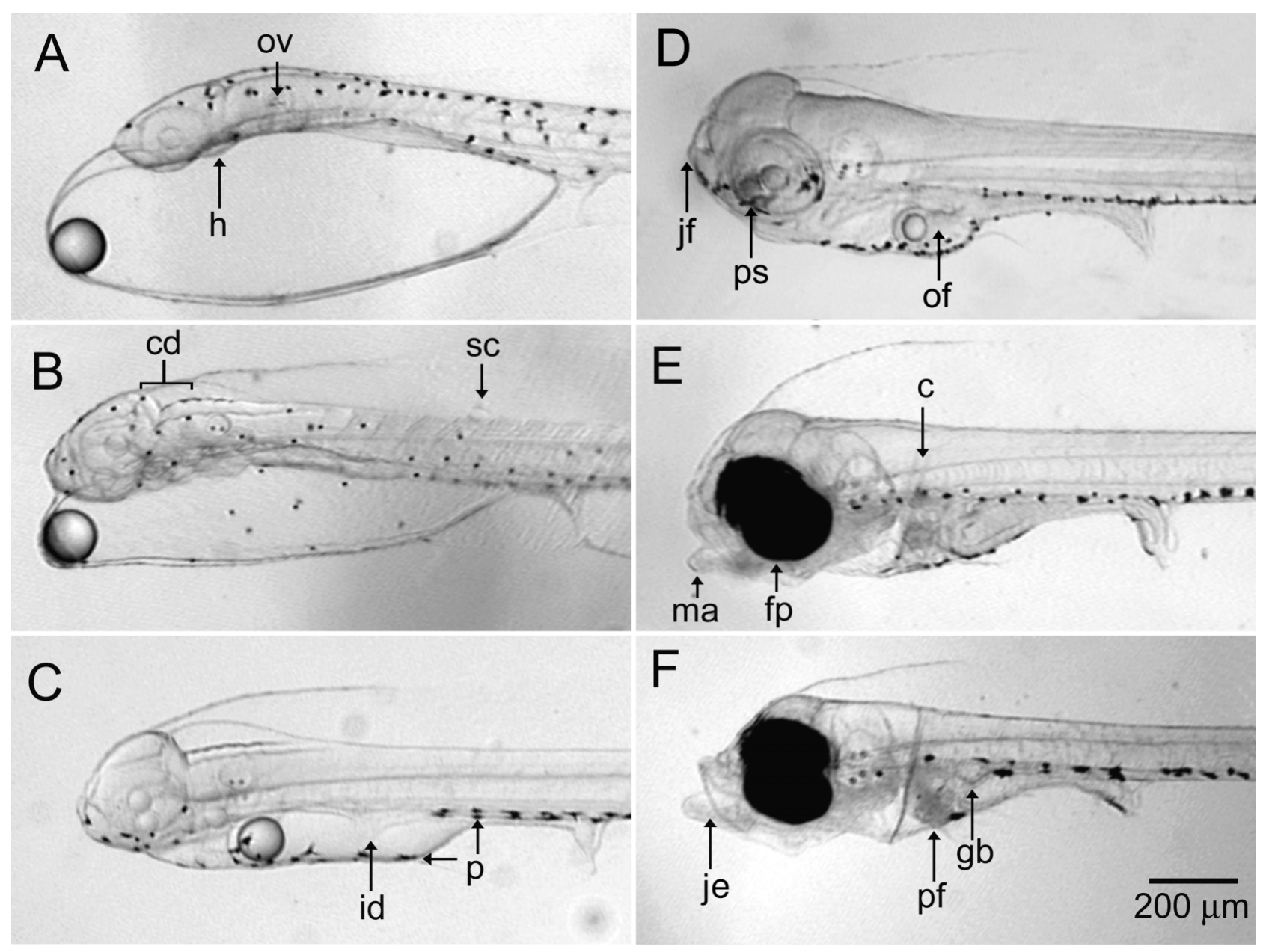

Fig. 5. Lutjanus campechanus. Development of morphological events during yolk-sac larval stage. (A) Larva at hatch, $24 \mathrm{~h}$ postfertilization (hpf) (h: heart beating; ov: otic vesicle); (B) at 32 hpf (cd: cranial development; sc: sensory cupolae); (C) at 42 hpf (id: intestinal development; p: melanophore migration); (D) at 55 hpf (jf: jaw formation; of: organ formation; ps: start of orbit pigmentation); (E) at 70 hpf (c: cleithrum; fp: full orbit pigmentation; ma: articulated mouth); (F) at 120 hpf (gb: gas bladder inflated; je: jaw elongation; pf: pectoral fin

\section{DISCUSSION}

Larval development of red snapper is similar to that of other described snapper species (Suzuki \& Hioki 1979, Lim et al. 1985, Hamamoto et al. 1992, Doi et al. 1994, Riley et al. 1995). The yolk utilization pattern approximates that of other marine larvae that contain visible oil globule(s). The slower utilization rate of the oil globule relative to the yolk-sac supports its suggested function as the primary energy source for the developing larva (Ronnestad et al. 1994, 1998, Fyhn \& Govoni 1995). The increase in the rate of oil globule utilization at 6 to $9 \mathrm{hpf}$ corresponded to extensive cranial differentiation and the laying down of muscle fibrils in the developing larva (Woodard 2003). In this developmental period the formation of the sensory cupolae occurred, which may allow the larvae to sense pressure changes (Doi et al. 1994). These developmental events increase the coordinated locomotive ability of larvae, which may result in increased neutral lipid metabolism. The extreme anterior placement of the oil globule inside the yolk-sac after hatch, observed in most snapper larvae, could represent a buoyancy regulation mechanism, as it gives larvae a greater capacity for vertical orientation in the water column in the earliest stages, when vision is not yet developed.

The rapid rate of yolk-sac absorption following hatching corresponded to the greatest increase in larval length (Fig. 3). Monitoring of larval length revealed a period of stasis and length loss preceding firstfeeding, with rapid growth not being resumed until feeding became established, as seen in other marine 
larvae (Mihelakakis et al. 2001, Moteki et al. 2001). A reduction in length of pre-feeding larvae has been reported by Doi \& Singhagraiwan (1993) for the mangrove red snapper Lutjanus argentimaculatus and for John's snapper L. johni (Lim et al. 1985). During flexion, red snapper larvae exhibit another period of slowed increase in length; however, during this period growth is channeled toward an increase in body depth (Drass et al. 2000). Allometric growth of the trunk length in relation to $L_{S}$ in early larvae is a described occurrence (Gisbert et al. 2002), and is due to the faster development of the necessary feeding and locomotive structures (Osse et al. 1997).

Continued development in red snapper was observed after the exhaustion of visually apparent endogenous reserves. This suggests a disparity between visible nutrient mobilization and actual utilization for growth at the cellular level, or a restructuring of tissues. The rate of yolk-sac utilization corresponds to the 'intensity' of development, as the period of greatest change in larval appearance, organ and structure development corresponds with the greatest reduction in yolk-sac volume. Continual development of the jaw apparatus observed in larvae that were not fed may reflect this developmental emphasis, as continued development of jaw structures may occur at the expense of other tissues already laid down. Loss of body tissues, evidenced by a reduction in body length and width, may not only represent a metabolic need (Rogers \& Westin 1981, Ronnestad et al. 1994), but also a restructuring into increasing jaw elements, allowing the larva to utilize somewhat larger prey that may be present in its environment but inaccessible at firstfeeding. Other body parts, such as the pectoral fins and digestive tract, develop extensively after the yolk-sac has been consumed.

Some degree of tissue resorption prior to full yolk utilization has been observed in several pelagic spawning marine fishes (Quantz 1985), and is considered a normal part of the larval development cycle (Jaworski \& Kamler 2002). Wright \& Fyhn (2001) discussed the increase in protein metabolism at the endpoint of yolksac resources in marine fish larvae; this increase may better prepare the larva for digesting its first prey. However, if a greater fraction of proteins used for metabolic needs arises from tissue resorption, as opposed to the yolk reserves, this may enhance the critical nature of the first-feeding event. Red snapper larvae absorb their yolk-sacs at a much earlier development stage than some commonly cultured species such as the sea bass Latex calcarifer (Kohno et al. 1986). A decrease in body dimensions starts at the end of the yolk sac stage, with $25 \%$ of the development time from fertilization to jaw articulation still remaining. This suggests that the amount of yolk reserves is likely to be minimally suffi- cient to allow the larvae to develop to a point where exogenous nutrition can be utilized.

Larvae of different species can vary in their resilience to starvation (McGurk 1984). Larvae with endogenous reserves that extend beyond first-feeding, as in the sea bass Lates calcarifer, may not experience a slowing of growth at first-feeding, but may have a constant protein supply to fuel growth (Kohno et al. 1986, Avila \& Juario 1987). Bagarinao (1986) reported a positive correlation between the amount of endogenous reserves and survival of 3 species of warm-water marine fishes in a hatchery. Larvae of the European sea bass Dicentrarchus labrax still possess $30 \%$ of their initial oil globule volume at the presumed onset of feeding (Ronnestad et al. 1998), and the red porgy Pargus pargus retains $5 \%$ of its oil reserves at the onset of feeding (Mihelakakis et al. 2001). Rogers \& Westin (1981) stated that striped bass Morone saxilis larvae contain an unusually large oil globule that is retained well into feeding, and presumably may lessen starvation risk in this species.

Suzuki \& Hioki (1979) and Hamamoto et al. (1992) reported that little or no yolk matter was present when the functional mouth parts formed in the bluestripe snapper Lutjanus kasmira and the spotted snapper $L$. stellatus. Our findings indicate a similar pattern in the red snapper, with the yolk-sac being exhausted early in development. In contrast, Doi \& Singhagraiwan (1993) reported $28 \%$ of the initial globule volume present at first-feeding (75 hpf) in the mangrove red snapper L. argentimaculatus, the most commonly cultured snapper species. The period of time a larva has to find food is directly related to the length of the transitional feeding period, and apparently may vary even among species within the same genera. The lack of a standard endogenous-resource measurement and development observation techniques prevent a robust comparison among species, but the general tendency of lower yolk-sac resources is seen within the lutjanid group.

This study also explored the practicability of using images of live larvae as a basis for morphological work. The use of an image-based sampling system allowed high-precision measurements of morphometric characters to be obtained. Image-based morphometry can be a useful tool for determining the relative condition of larvae (Reichow et al. 1991). Further precision is added by the use of live larvae, since this avoids potential effects of preservatives, which can be substantial and can introduce additional variance to measurements (Jennings 1991, Takizawa et al. 1994). The factor most strongly influencing larval length may be mortality, as the physiological aspects of the loss of active osmoregulation at the microscopic scale can cause significant loss in larval length (Radke 1989). 
Larval mortality at first feeding remains a fundamental challenge for the culture and artificial propagation of red snapper. Red snapper larvae show evidence of starvation within hours of the appearance of functional mouth parts. The observed reductions in larval body parameters may be symptomatic of tissue resorption, and suggest that red snapper larvae may be more sensitive to starvation than commonly cultured fish species. Further advances in larval rearing protocols are likely to come from an improved understanding of the reproductive life history and the energetic dynamics of the prefeeding stages.

Acknowledgements. This study was conducted with the assistance of the staff of the Alabama Marine Resources of the Alabama Department of Conservation working at Claude Peteet Mariculture Research Station in Gulf Shores, Alabama. We are very grateful for additional helpful recommendations and suggestions from D. Maus, M. Ross and B. Bourque of Auburn University, and for support from the USDA Grant 2001-34421-10376.

\section{LITERATURE CITED}

Avila EM, Juario JV (1987) Yolk and oil globule utilization and developmental morphology of the digestive tract epithelium in larval rabbitfish (Siganus guttatus B.). Aquaculture 65:319-331

Bagarinao T (1986) Yolk resorption, onset of feeding and survival potential of larvae of three tropical marine fish species reared in the hatchery. Mar Biol 91:449-459

Blaxter JHS (1986) Development of sense organs and behavior of teleost larvae with special reference to feeding and predator avoidance. Trans Am Fish Soc 115:98-114

Bootes K (1998) Culture and description of larval red snapper, Lutjanus campechanus. MSc thesis, Auburn University, Auburn, AL

Doi M, Singhagraiwan T (1993) Biology and culture of the red snapper, Lutjanus argentimaculatus. The research project of fishery resource development in the kingdom of Thailand, The Eastern Marine Fisheries Development Center EMDEC, Department of Fisheries, Ministry of Agriculture and Cooperatives, Thailand, p. 51

Doi M, Kohno H, Taki Y, Ohno A, Singhagraiwan T (1994) Morphological development of eggs, larvae, and juveniles of the red snapper, Lutjanus argentimaculatus (Pisces: Lutjanidae). J Tokyo Univ Fish 81:135-153

Drass DM, Bootes KL, Lyczkowski-Shultz J, Comyns BH, Holt GJ, Riley CM, Phelps RP (2000) Larval development of red snapper, Lutjanus campechanus, and comparisons with co-occurring snapper species. Fish Bull US 98:507-527

Emata AC, Eullaran B, Bagarinao TU (1994) Induced spawning and early life description of the mangrove red snapper, Lutjanus argentimaculatus. Aquaculture 121:381-387

Fyhn HJ, Govoni JJ (1995) Endogenous nutrient mobilization during egg and larval development in two marine fishes Atlantic menhaden and spot. ICES J Mar Sci 201:64-69

Gisbert E, Merino G, Muget JB, Bush D, Piedrahida RH, Conklin DE (2002) Morphological development and allometric growth patterns in hatchery-reared California halibut larvae. J Fish Biol 61:1217-1229

Hamamoto S, Kumagai S, Nosaka K, Manabe S, Iwasuki Y
(1992) Reproductive behavior, eggs and larvae of a lutjanid fish, Lutjanus stellatus, observed in an aquarium. Jpn J Ichthyol 39:219-227

Jaworski A, Kamler E (2002) Development of a bioenergetics model for fish embryos and larvae during the yolk feeding period. J Fish Biol 60:785-809

Jennings S (1991) The effects of capture, net retention and preservation upon lengths of larval and juvenile bass, Dicentrarchus labrax (L.). J Fish Biol 38:349-357

Kimmel CB, Ballard WW, Kimmel SR, Ullmann B, Schilling TF (1995) Stages of embryonic development of the zebrafish. Dev Dyn 203:253-310

Kohno H, Hara S, Taki Y (1986) Early development of the sea bass, Lates calcarifer, with emphasis on the transition of energy sources. Nippon Suisan Gakkaishi 52:1719-1725

Lim LC, Cheong L, Lee HB, Heng HH (1985) Induced breeding studies of the John's snapper, Lutjanus johni (Bloch), in Singapore. Singap J Prim Ind 13:70-83

McGurk MD (1984) Effects of delayed feeding and temperature on the age of irreversible starvation and on the rates of growth and mortality of Pacific herring larvae. Mar Biol 84:13-26

Mihelakakis A, Yoshimatsu T, Tsolkas C (2001) Spawning in captivity and early life history of cultured red porgy, Pagrus pagrus. Aquaculture 199:333-352

Minton RV, Hawke JP, Tatum WM (1983) Hormone induced spawning of red snapper, Lujanus campechanus. Aquaculture 30:363-368

Moteki M, Yoseda K, Sahin T, Ustundag C, Kohno H (2001) Transition from endogenous to exogenous nutritional sources in larval Black Sea turbot Psetta maxima. Fish Sci 67:571-578

Osse JWM, van den Boogart JGM, van Snik GMJ, van der Sluys L (1997) Priorities during early growth of fish larvae. Aquaculture 155:249-258

Quantz G (1985) Use of endogenous energy sources by larval turbot Scophthalamus maximus. Trans Am Fish Soc 114: 558-563

Rablais NN, Rablais SC, Arnold CR (1980) Description of eggs and larvae of laboratory reared red snapper (Lutjanus campechanus). Copeia 4:704-708

Radke RL (1989) Larval fish age, growth and body shrinkage, information available from otoliths. Can J Fish Aquat Sci 46:1884-1894

Reichow D, Largiader C, Klingenberg C, Clemmesen C, Froese R, Ueberschaer B (1991) The use of multivariate morphometrics to determine the nutritional condition for marine fish larvae. ICES Council Meetings Papers. ICES, Copenhagen

Riley CM, Holt GJ, Arnold CR (1995) Growth and morphology of larval and juvenile captive bred yellowtail snapper, Ocyurus chrysurus. Fish Bull US 93:179-185

Rogers BA, Westin DT (1981) Laboratory studies on effects of temperature and delayed initial feeding on development of striped bass larvae. Trans Am Fish Soc 110:100-110

Ronnestad I, Koven WM, Tandler A, Harel M (1994) Energy metabolism during development of eggs and larvae of gilthead sea bream (Sparus aurata). Mar Biol 120:187-196

Ronnestad I, Koven WM, Tandler A, Harel M, Fyhn H (1998) Utilization of yolk fuels in developing eggs and larvae of European sea bass (Dicentrarchus labrax ). Aquaculture 162:157-170

Suzuki K, Hioki S (1979) Spawning behavior, eggs, and larvae of the lutjanid fish, Lutjanus kasmira, in an aquarium. Jpn J Ichthyol 26:161-166

Takizawa K, Fujita Y, Ogushi Y, Matsuno S (1994) Relative change in body length and weight in several fish due to formalin fixation and preservation. Fish Sci 60:355-359 
Watanabe WO, Feeley MW, Ellis SC, Ellis EP (1998) Light intensity and salinity effects on eggs and yolk-sac larvae of the summer flounder. Prog Fish-Cult 60:9-19

Woodard A (2003) Morphological development of the red snapper Lutjanus campechanus. MSc thesis, University of

Editorial responsibility: Otto Kinne (Editor),

Oldendorf/Luhe, Germany
South Alabama, Mobile

Wright PA, Fhyn HJ (2001) Ontogeny of nitrogen metabolism and excretion. In: Wright PA, Anderson PM (eds) Fish physiology, Vol 20. Nitrogen excretion. Academic Press, New York, p 149-200

Submitted: September 19, 2003; Accepted: March 9, 2004

Proofs received from author(s): June 15, 2004 